\title{
Spatial clustering and meso-scale correlates of thyroid disorder among women in India: evidence from the National Family Health Survey (2015-16)
}

\author{
Shri Kant Singh ${ }^{1}$ (D) $\cdot$ Aditi Aditi $^{1}$ (D) Jitendra Gupta ${ }^{1}$ (ID \\ Received: 3 September 2020 / Accepted: 8 June 2021 / Published online: 24 June 2021 \\ (C) The Author(s) 2021
}

\begin{abstract}
Purpose Thyroid disorders are a major public health burden. Generally, women exhibit higher differentials in the prevalence of these disorders. This study focuses on the socio-economic and behavioural correlates of thyroid disorders along with their spatial clustering among women of reproductive age in India.

Methods The study uses dataset from the fourth National Family Health Survey (NFHS-4) carried out in 2015-16 to assess selfreported thyroid disorders. Poor-rich ratio (PRR) and concentration index (CI) were used to study the variation in thyroid disorder among women arising out of economic inequality. Moran's I statistics and bivariate local spatial autocorrelation (BiLISA) maps were used to understand spatial dependence and clustering of thyroid disorder. Spatial lag and error models were applied to examine the correlates of the disorder.

Results Thyroid disorder prevalence was higher among women from socio-economically better-off households. Adjusted effects showed that users of iodized salt were 1.14 times more likely to suffer from a thyroid disorder as compared to non-users, which is contrary to the general belief that a higher percentage of consumption of iodide salt leads to a lower prevalence of thyroid disorder. A higher autoregressive coefficient (0.71) indicated significantly higher spatial clustering in thyroid disorders.

Conclusions The prevalence of thyroid disorder in India depends appreciably on spatial and various ecological factors. Sedentary lifestyles among women may be aggravating diseases, which has strong linkage with thyroid disorders. It is strongly recommended to effectively integrate universal salt iodization with activities geared towards the elimination of iodine deficiency disorders.
\end{abstract}

Keywords Thyroid disorder (TD) · Universal salt iodization (USI) · Iodine deficiency disorder (IDD) · Autocorrelation · Spatial analysis

\section{Introduction}

The thyroid is a butterfly-shaped endocrine gland situated in the anterior aspect of the neck, below the Adam's apple. The

Aditi Aditi

aditi.chaudhary72@gmail.com

Shri Kant Singh

sksingh31962@gmail.com

Jitendra Gupta

jiitend@gmail.com

1 Department of Mathematical Demography and Statistics, International Institute for Population Sciences,

Mumbai, Maharashtra 400088, India function of this gland is to produce the thyroid hormones, triiodothyronine (T3) and thyroxine (T4), which are required for metabolic processes, protein synthesis, healthy development, and maturation of the brain during the fetal stage and the first few years of life (Hall 2015; Kapil 2007). Thyroid disorders are common worldwide, and in India too a significant burden of these disorders exists. According to an estimate based on various studies of thyroid disease, about 42 million people in India suffer from it. Dietary iodine is essential for the synthesis of thyroid hormones. A shortfall of physiological requirements of iodine causes various anomalies in the body, including thyroid function abnormalities and in severe cases, endemic goiter, cretinism, endemic mental retardation, decreased fertility rates, increased perinatal deaths, and infant mortality. Together, these complications are grouped under iodine deficiency disorders (IDD) (Hall 2015). Widespread 
iodine deficiency in any population poses a significant threat to economic development and slows down progress towards health for all, particularly in developing countries (Engle et al. 2007; Unnikrishnan and Menon 2011). Given the extent of thyroid disease and the critical importance of iodine, a sustained strategy to mitigate iodine deficiency is required.

In general, women exhibit higher differentials across background characteristics in the prevalence of goitre. A study by the International Institute for Population Sciences (IIPS), Mumbai found that the incidence of goitre was almost twice as high among urban women as among rural women (IIPS 2007). Women are also more likely to be iodine deficient and hence vulnerable to thyroid problems. Those pregnant or breastfeeding are usually at a higher risk since their standard requirement of iodine is greater (Mioto et al. 2018; WHO 2001). In such cases, deficiency causes underdevelopment of the fetus (Diosady et al. 1998). Universal salt iodization (USI) has been recognized as the most promising and sustainable solution to address this deficiency. When $90 \%$ of households consume adequately iodized salt ( $15 \mathrm{ppm})$, the country is declared 'universally iodized'. The concept of USI as a solution has been introduced globally, since salt serves as an inevitable staple condiment consumed by all, independent of caste, class, and social status (Miller et al. 1967). By the year 2010, around $74 \%$ of the world population had access to iodized salt and were largely able to eliminate IDDs (Levi et al. 1991). However, access to and use of adequately iodized salt varies sharply within regions and countries, and IDD continues to be an immense public health problem.

The literature suggests that the rates of thyroid disorder (TD) differ not only according to the regions, but also depends on differences such as individual-level demographic factors, economic status, culture, and attitudes. In India, caste, next to income (poverty), has remained the centre of a large number of studies to understand disparity on various health outcomes. The strict caste system leads to lower castes being deprived and disadvantaged. This is responsible for differentials in the health outcome and healthcare behaviour among the deprived. The Indian caste system is divided into scheduled tribe (ST), scheduled caste (SC), other backward castes (OBC) and other castes. SCs and STs are historically disadvantaged social groups and are constitutionally recognized in India to be marginalised (Bora et al. 2019; Raushan and Mutharayappa 2014).

Some studies claim that thyroid hormone concentrations fluctuate according to body-fat levels and overeating (Miller et al. 1967; Sims et al. 1973). A positive and significant correlation exists between serum $\mathrm{T} 3$ and the percentage of body fat. People having a body mass index (BMI) of more than 25 were significantly more likely to be suffering from the disorder. Studies have also shown that no correlation exists between bodyweight and serumT4 (Bray et al. 1976; Rhyne and Gehlbach 1979; Schectman et al. 1991).
Studies discuss the importance of education as a significant intervention in thyroid hormone-related disorder (Rhyne et al. 1979; Schectman et al. 1991). In TD endemic regions, a high probability of suffering from the disorder exists, even among the wealthiest inhabitants. A substantial geographical variation in both iodine deficiency and hence thyroid disorder also persists (Meisinger et al. 2012). The disorder is typically reported from mountainous regions such as the Himalayas, the Alps, and the Andes, as well as from plain regions which are frequently exposed to flooding, and large river delta regions such as those of the Ganges, Yellow River, and Rhine (Ciarrocca et al. 2012; Guay et al. 2014). The disorder is also a prominent problem where food and water are naturally deficient in iodine.

To our knowledge, there has been no systematic effort to date to study the spatial variation in thyroid disorders across the 640 districts of India, despite the several rounds of largescale, national-level surveys available. The purpose of this study is to examine three issues, namely the prevalence of use of iodized salt among households and associated prevalence of thyroid disorders among women in India in 2015-16, the association between background characteristics and thyroid disorder prevalence in India, and lastly the existence of spatial dependence, if any, on the prevalence of thyroid disorder among women aged 15-49 years in India. The uniqueness of the present study is in addressing these issues through an investigation of the socio-economic and behavioral determinants of thyroid disorders in India along with spatial dependence and clustering.

\section{Methods}

\section{Data source}

The data for the present study was from the fourth round of the National Family Health Survey (NFHS-4), conducted during 2015-16 under the stewardship of the Ministry of Health and Family Welfare (MoHFW), Government of India, and coordinated by the International Institute of Population Sciences (IIPS), Mumbai. The NFHS is a large-scale, multi-round survey conducted in a nationally representative sample of households. It provides national and state-level data for India on infant and child mortality, fertility, reproductive health, maternal and child health, nutrition, anaemia, thyroid, asthma, and family planning services. The NFHS-4 used a stratified two-stage sampling design, which yielded state-representative samples after applying weights to control for the complex survey design. This survey collected information from a nationally representative sample of 601,509 households, from 699,686 women aged 15-49 years, 204,735 from urban and 494,951 from rural areas, with an overall response rate of 98\%. The participants gave their consent for conducting 
interviews and the use of the data for research purposes. All interviewed women aged 15-49 years provided information on thyroid disorders. Salt was tested in all households for the presence or absence of potassium iodate or potassium iodide. The data on the emerging health issues with regard to thyroid for each of the 640 districts in the country is available in the public domain (IIPS and ICF 2017).

Outcome variable The outcome variable for the study was thyroid disorder among women aged 15-49 years. The prevalence of thyroid disorder was computed from the selfreported cases of the disease, from a sample of women. Among the 699,686 women included in the study, 15,303 women reported suffering from thyroid disorder at the time of the survey.

Independent variables Based on the existing literature and the availability of data, several determinants of thyroid disorder were selected for this study. These included households using iodized salt, educational level, place of residence (urban or rural), caste, religion, regional division, wealth quintile, and mass media exposure.

Statistical measures Bivariate analysis was the tool used to ascertain the prevalence of thyroid disorder in various states, regions, and districts of India and to determine any unadjusted associations between the selected socio-economic, demographic, and biological factors and thyroid.

Variation in TD among women arising out of economic inequality was examined using the poor-rich ratio (PRR) and concentration index (CI). The PRR was analysed by using the poorest and most prosperous wealth quintiles. The $\mathrm{CI}$ is a measure of inequality and is defined as twice the area between the concentration curve and the diagonal; it varies between -1 and +1 (Wagstaff and Doorslaer 2004). There is equality, $\mathrm{CI}=0$ when the line of concentration curve lies above the diagonal. The more the line deviates from the diagonal in either direction, towards -1 or +1 , the higher the inequality. Concentration curves and CIs are methods used to measure overall inequality in particular health outcome among the wealth quintiles (Kakwani et al. 1997).

Spatial analysis ArcGIS version 10.1 and GeoDa version 1.6.7 software was employed for the spatial analysis, with ArcGIS also being used to merge the maps and data, and STATA 14 for rest of the data analysis. Univariate and bivariate local Moran's I statistics were computed with the help of GeoDa for each independent variable. Moran's I is a measure of spatial autocorrelation that is derived as a generalization of the Pearson's correlation coefficient. Spatial autocorrelation indicates the degree to which data points are similar or dissimilar to their spatial neighbours, and also identifies clusters. Moran's I is given by:
Moran's I $=\mathrm{C} \times \frac{\sum \sum w_{i j} z_{i} z_{j}}{\sum \mathrm{z}_{\mathrm{i}}^{2}}$

where $z_{\mathrm{i}}$ is the variable of interest, $w_{\mathrm{ij}}$ are elements of the standardized weight matrix and multiplier $C=n / \mathrm{S}_{0}$ where $\mathrm{n}$ is the number of observations in the variable and $\mathrm{S}_{0}$ is the sum of the weights.

Positive spatial autocorrelation indicates that points with similar attribute values are closely distributed in space, whereas negative spatial autocorrelation indicates that closely associated points are more dissimilar. Values range from -1 (indicating perfect dispersion) to +1 (perfect correlation). A value of zero indicates a random spatial pattern. Univariate local indicators of spatial association (LISAs) measure the correlation of neighborhood values around a specific spatial location. The purpose of bivariate local spatial autocorrelation (BiLISA) is to analyse the association of selected characteristics of regions with different outcomes. It is a type of cluster map with different types of spatial autocorrelation, namely red for hotspots, deep blue for cold spots, and light blue and light red are spatial outliers.

The present study explored the significant variants of thyroid disorder. At the primary level, the ordinary least square (OLS) regression with TD was conducted, and the extent of spatial autocorrelation in the error term, and the corresponding Moran's I statistic were estimated. The OLS indicates the spatial autocorrelation in its error term for a thyroid disorder, allowing a spatial error model (SEM) to be estimated. The assumption of a spatial lag model represents the observations of the dependent variable affecting the neighborhood areas, and the spatial error model is used to consider the effect of those variables, which are not present in the regression model but still influence the outcome variable. The basic difference between the two models is that the spatial lag model, unlike the spatial error model, does not consider spatial dependency in the error term. Diagnostics tests for spatial dependence gave values of the Lagrange multiplier that were significant in both models $(p<0.001)$. As a result, robust Lagrange multiplier (LM) (lag) and robust LM (error) were compared. The larger value of robust LM (error) compared with robust LM (lag), and a larger value of adjusted $\mathrm{R}^{2}$ explain better model adequacy. The model also gave lower values of the Akaike information criterion (AIC) and the Schwarz criterion. This justified the suitability of the model, and the decision to choose the LM (error) model to analyse the spatial dependency of thyroid disorder with various predictors included in the model.

Spatial lag model The spatial lag model incorporates the influence of unmeasured independent variables and stipulates an additional effect of neighboring attribute values, i.e., lagged dependent variables (a thyroid disorder):

$Y=\rho W y+X \beta+\varepsilon$ 
where $W y$ is an $\mathrm{N} \times 1$ vector of spatial lags for the dependent variable, $\rho$ (rho) is the spatial autoregressive coefficient, and a scalar parameter that indicates the effect of the dependent variable in the neighbours on the dependent variable (a thyroid disorder) in the focal area; $X \beta$ is an $N \times K$ matrix of observations on the exogenous explanatory variables multiplied by a $K \times 1$ vector of regression coefficient $\beta$ for each $X$, and $\varepsilon$ is an $N \times 1$ vector of normally distributed random error terms.

Spatial error model The spatial error model evaluates the extent to which the clustering of an outcome variable (a thyroid disorder) not explained by measured independent variables can be accounted for, based on the clustering of error terms. In this sense, it captures the influence of unmeasured independent variables. The spatial error model takes the form described by two equations:

$y=X \beta+\varepsilon$ and $\varepsilon=\lambda W \varepsilon+u$

where $y$ is an $\mathrm{N} \times 1$ vector of observations on the dependent variable, $X$ is an $\mathrm{N} \times \mathrm{K}$ matrix of observations on the explanatory variables, $\beta$ is a $K \times 1$ vector of regression coefficients, $\varepsilon$ is an $\mathrm{N} \times 1$ vector of spatially lag auto-correlated error terms, $W \varepsilon$ is a spatial lag for the errors, $\lambda$ is the autoregressive coefficient, and $u$ is another error term (Anselin et al. 2010).

\section{Results}

The results of the present study on spatial heterogeneity in the prevalence of thyroid disorder among women in their reproductive ages (15-49 years) are based on a nationally representive sample of 699,686 women from all 36 states and union territories (UTs), covering 640 districts in India.

Salt iodization and prevalence of thyroid disorders The NFHS tested for the presence or absence of potassium iodate or potassium iodide in the salt used by the sample households (Table 1). Salt was tested in almost all households. More than nine in ten households $(93 \%)$ used iodized salt, which is a considerable increase from $74 \%$ of households using iodized salt a decade ago (IIPS 2007). However, the pattern in the use of iodized salt was not uniform across the various socio-economic groups. There was a steady increase in the use of iodized salt based on the educational status of women and their wealth quintiles, from $91 \%$ among women with no education to $96 \%$ among those having higher education, and $90 \%$ in the lowest wealth quintile to $98 \%$ in the highest wealth quintile. Exposure to mass media had some association with the intake of iodized salts in the households, since $94 \%$ of women who had mass media exposure reported
Table 1 Percentage of women aged 15-49 years whose household consumed iodized salt by some selected background characteristics, India 2015-16

\begin{tabular}{|c|c|}
\hline Background characteristic & Percent $(N=699,686)$ \\
\hline \multicolumn{2}{|l|}{ Level of education } \\
\hline No education & 90.7 \\
\hline Primary & 92.3 \\
\hline Secondary & 94.2 \\
\hline Higher & 96.5 \\
\hline \multicolumn{2}{|l|}{ Place of residence } \\
\hline Urban & 96.3 \\
\hline Rural & 91.7 \\
\hline \multicolumn{2}{|l|}{ Caste } \\
\hline $\mathrm{SC}$ & 92.1 \\
\hline ST & 91.6 \\
\hline $\mathrm{OBC}$ & 92.8 \\
\hline Other & 95.5 \\
\hline \multicolumn{2}{|l|}{ Religion } \\
\hline Hindu & 92.8 \\
\hline Muslim & 94.9 \\
\hline Other & 95.6 \\
\hline \multicolumn{2}{|l|}{ Region } \\
\hline Eastern & 94.5 \\
\hline Western & 95.5 \\
\hline Northern & 94.6 \\
\hline Southern & 87.7 \\
\hline North-eastern & 99.4 \\
\hline Central & 93.1 \\
\hline \multicolumn{2}{|l|}{ Wealth index } \\
\hline Poorest & 89.9 \\
\hline Poorer & 90.9 \\
\hline Middle & 91.9 \\
\hline Richer & 95.4 \\
\hline Richest & 97.6 \\
\hline \multicolumn{2}{|l|}{ Mass media } \\
\hline No & 90.7 \\
\hline Yes & 93.9 \\
\hline India & 93.3 \\
\hline
\end{tabular}

SC: scheduled caste, ST: scheduled tribe, OBC: other backward castes

using iodized salt in comparison to $91 \%$ who did not have any media exposure. A relatively lower proportion of women from the southern region used iodized salt in their households.

Figure 1 presents the spatial variation in the use of iodized salt. The consumption of iodized salt was lowest in Andhra Pradesh, Tamil Nadu, and Dadra and Nagar Haveli at 82, 83, and $71 \%$ respectively. Universal salt iodization with a prevalence of over $95 \%$ of households could be observed in the states of Kerala, Gujarat, Maharashtra, Goa, and states such as Chhattisgarh, Jharkhand, Sikkim, Assam, and others, with only a few southern states in the country having less than $90 \%$ 
Fig. 1 Map showing the percentage of households reporting consumption of Iodized salt in different states/union territories of India, 2015-16. Note: this map is indicative and does not portray the political/ administrative boundaries of India. Some districts of Jammu and Kashmir have no data coverage in the GADM database [GADM database of Global Administrative Areas: GADM maps and data (2018)]

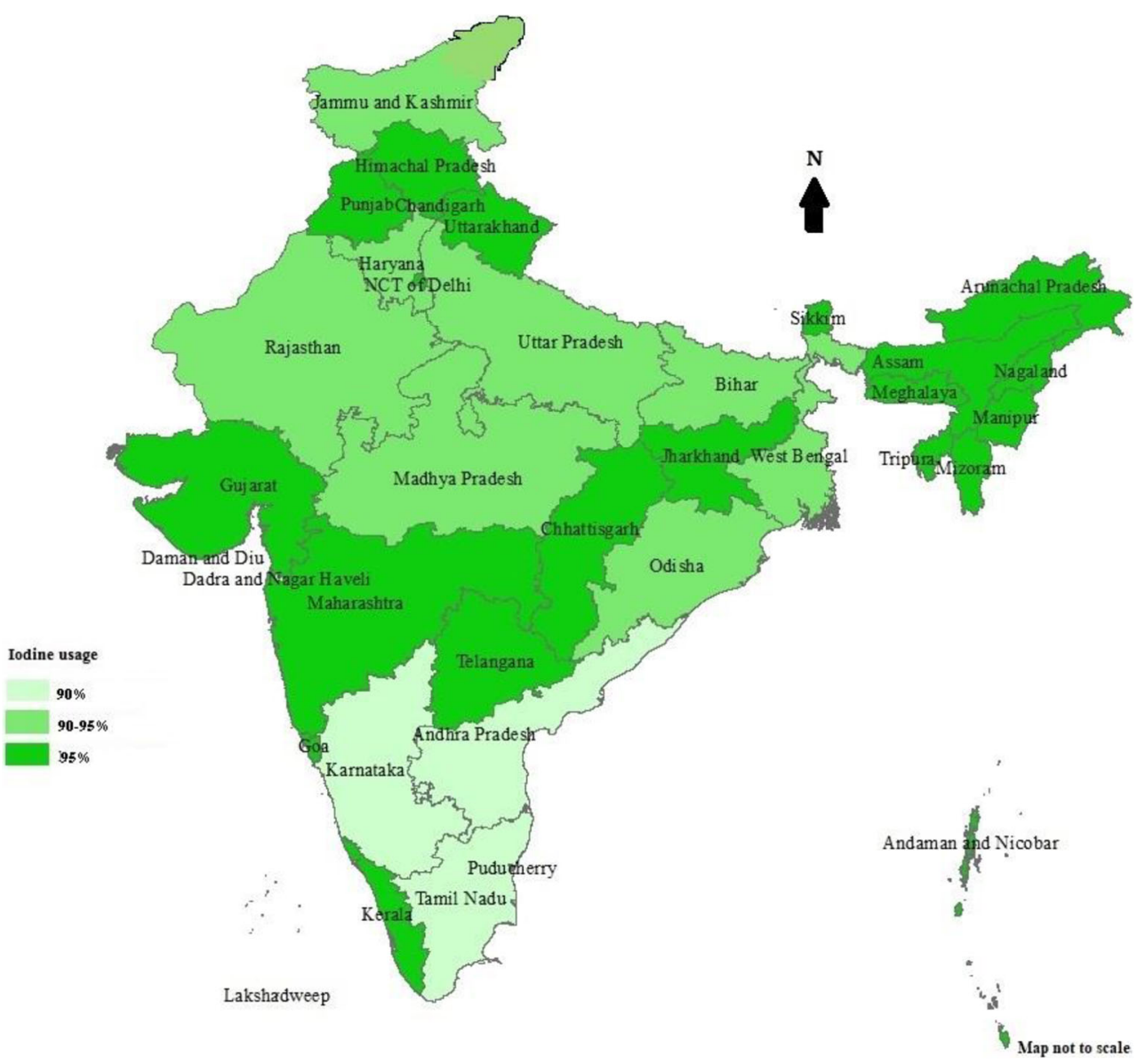

iodized salt usage. Despite governmental efforts, we found that there were still $7 \%$ of households consuming noniodized salt. The higher requirement of iodine during pregnancy and childbirth makes women in the reproductive age group and their offspring more vulnerable due to the absence of iodized salt. Iodine disorder has a huge impact on public health (WHO 2007).

Table 2 presents the prevalence and determinates of thyroid disorder among women aged 15-49 years in India. For the entire country, $2.2 \%$ reported suffering from goitre or other thyroid disorders. The variation in the prevalence of thyroid disorder was analysed using selected socio-economic and behavioral characteristics. The results of the association between the consumption of iodized salt and the prevalence of thyroid disorder are contrary to theoretical belief. Women from households using iodized salt were found to be more likely to be suffering from thyroid disorder $(2.2 \%)$ as compared to those not using iodized salt (1.6\%). This result remained unaltered even after adjusting for other predictors included in the model with odds ratio $(\mathrm{OR})$ here $(\mathrm{OR}=1.14 ; p<0.01)$. It is also worth mentioning that women belonging to economically better-off households belonging to non-scheduled caste/ scheduled tribe (non-SC/ST) and non-other backward caste (non-OBC) and Muslim religion were more likely to suffer from thyroid disorder, a conclusion which holds even after adjusting for various predictors included in the logistic regression model. Further, results showed that women from the southern region and residing in urban areas,were significantly more likely to have thyroid disorder than those living in rural areas.

Figure 2 shows the district-wise quintile map of thyroid disorders. Darker districts portray a higher prevalence of thyroid disorder. Of all 640 districts, 128 with the highest prevalence were home to $2.9 \%$ to $15.3 \%$ of people affected. The next quintile covers 127 districts having a $1.7 \%$ to $2.9 \%$ prevalence of thyroid disorder. We were able to show that 255 out of 640 districts in the country had thyroid disorder in the range of $1.7 \%$ to $15.3 \%$.

Kasaragod, Kannur, Wayanad, Kozhikode, Malappuram, Thiruvananthapuram, Kollam, Alappuzha, Pathanamthitta, and Kottayam in Kerala; Nellore, East Godwari, Kadapa, Chittoor, Srikakulam, Vishakhapatnam, Adilabad, Nizamabad, Karimnagar, and Mahbub Nagar in Andhra Pradesh and Telangana; Thoothukudi, Ramanathapuram, Tirunelveli, and Kanyakumari in Tamilnadu; Murshidabad, Howrah, and Hooghly in West Bengal; Chandel, Ukhrul, Bishnupur, and East and West Imphal in Manipur; Rajouri, Poonch, Sopore, and Budgam in Jammu and Kashmir are 
Table 2 Adjusted prevalence of thyroid disorder among women aged 15-49 years by some selected background characteristics, India 2015-16

\begin{tabular}{|c|c|c|c|c|}
\hline \multirow[t]{2}{*}{ Background characteristics } & \multirow[t]{2}{*}{ Thyroid disorder $(N=15,303)$} & \multirow[t]{2}{*}{ Odds ratio } & \multicolumn{2}{|c|}{$95 \% \mathrm{CI}$} \\
\hline & & & Lower & Upper \\
\hline \multicolumn{5}{|l|}{$\mathrm{HH}$ using iodide salt } \\
\hline $\mathrm{No} \circledast$ & 1.6 & & & \\
\hline Yes & 2.2 & $1.14 * * *$ & 1.04 & 1.24 \\
\hline \multicolumn{5}{|l|}{ Level of education } \\
\hline No education ${ }^{\circledR}$ & 1.5 & & & \\
\hline Primary & 2.0 & 0.96 & 0.90 & 1.02 \\
\hline Secondary & 2.3 & $0.82 * * *$ & 0.78 & 0.86 \\
\hline Higher & 3.6 & $0.84 * * *$ & 0.79 & 0.90 \\
\hline \multicolumn{5}{|l|}{ Place of residence } \\
\hline Urban $®$ & 3.5 & & & \\
\hline Rural & 1.5 & $0.78 * * *$ & 0.75 & 0.82 \\
\hline \multicolumn{5}{|l|}{ Caste } \\
\hline $\mathrm{SC} \circledast$ & 1.9 & & & \\
\hline ST & 1.2 & $0.76 * * *$ & 0.70 & 0.82 \\
\hline $\mathrm{OBC}$ & 2.0 & $0.92 * * *$ & 0.87 & 0.97 \\
\hline Other & 3.1 & $1.45^{* * *}$ & 1.37 & 1.53 \\
\hline \multicolumn{5}{|l|}{ Religion } \\
\hline Hinduß & 2.1 & & & \\
\hline Muslim & 2.6 & $1.42 * * *$ & 1.36 & 1.49 \\
\hline Other & 3.2 & $1.18 * * *$ & 1.11 & 1.25 \\
\hline \multicolumn{5}{|l|}{ Region } \\
\hline Eastern ${ }^{\circledR}$ & 1.9 & & & \\
\hline Western & 1.4 & $0.56 * * *$ & 0.52 & 0.60 \\
\hline Northern & 2.0 & $0.92 * * *$ & 0.87 & 0.98 \\
\hline Southern & 3.7 & $1.55^{* * *}$ & 1.45 & 1.65 \\
\hline North-eastern & 1.8 & $1.15^{* * *}$ & 1.07 & 1.24 \\
\hline Central & 1.5 & $0.78 * * *$ & 0.71 & 0.84 \\
\hline \multicolumn{5}{|l|}{ Wealth index } \\
\hline Poorest ${ }^{\circledR}$ & 0.7 & & & \\
\hline Poorer & 1.1 & $1.39 * * *$ & 1.28 & 1.51 \\
\hline Middle & 1.8 & $1.76^{* * *}$ & 1.62 & 1.92 \\
\hline Richer & 2.7 & $2.45 * * *$ & 2.24 & 2.67 \\
\hline Richest & 4.3 & $3.88 * * *$ & 3.52 & 4.22 \\
\hline \multicolumn{5}{|l|}{ Mass media } \\
\hline No® & 0.9 & & & \\
\hline Yes & 2.5 & $1.37 * * *$ & 1.27 & 1.47 \\
\hline India & 2.2 & & & \\
\hline
\end{tabular}

Note: The values of the odds ratio are significant at $* * * p<0.01$ with respect to ®reference category. HH: household, CI: confidence interval, SC: scheduled caste, ST: scheduled tribe, OBC: other backward castes

some districts in the highest quintile of thyroid disorder. It is important to note that the spatial variation in the prevalence of thyroid disorder goes beyond the hotspots with low use of iodized salt. Only a few of the southern states were characterised by a lower prevalence of iodized salt consumption, but the concentration of districts with darker shades on Fig. 2 cuts across various states in the southern as well as eastern regions, and they are mostly located on the south-eastern coast. Some of the districts from the northern and central parts of the country also have a higher prevalence of thyroid disorder. These spatial variations, along with the adjusted effect of consuming iodized salt, indicate that prevalence of thyroid disorders in India goes much beyond the intake of iodized salts 
Fig. 2 Quintiles map portraying the prevalence of thyroid disorder among women aged $15-49$ years in different districts of India, 2015-16. Note: this map is indicative and does not portray the political/administrative boundaries of India. Some districts of Jammu and Kashmir have no data coverage in the GADM database [GADM database of Global Administrative Areas: GADM maps and data (2018)]. The numbers in square brackets are quintile divisions and the figures in parentheses are the number of districts in each category
Map 2 Quintiles map portraying the prevalence of Thyroid Disorder among women aged 1549 years in different districts of India, 2015-16

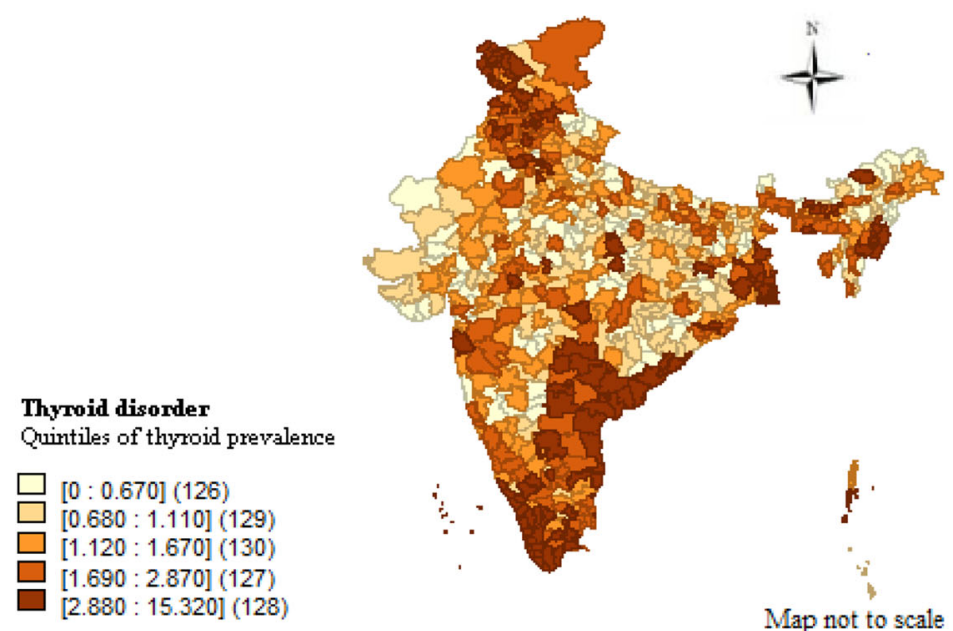

and is largely influenced by lifestyle, dietary practices, and other macro- and meso-correlates.

Economic inequality in thyroid disorder The existing age structural changes, coupled with the epidemiological shift in India, has resulted in health transition in the country with a dominance of lifestyle-based non-communicable diseases (NCDs), including various forms of thyroid disorders. An attempt is made in this section to analyse economic inequality as an explanatory factor in the prevalence of thyroid disorders among economic subpopulations. Monitoring and tackling inequalities in thyroid disorder and increased risks of associated complications such as obesity, coronary heart disease, stroke, etc., between socio-economic groups within countries has emerged as an increasingly important objective for various health interventions. This paper used two indicators, namely PRR and the Wagstaff concentration index, to arrive at a more definitive inference; the results are presented in Table 3. Economic inequalities related to thyroid disorder refer to the degree to which the prevalence of thyroid disorders differ between those who are at the two extreme ends of the wealth quintiles. The value of the PRR (0.17) and CI (0.33) significantly revealed that thyroid disorder was more concentrated among the richest women in India. Socio-economic inequalities with regard to the prevalence of thyroid disorder vary considerably across the states and geographical regions. At one end of the spectrum are the states of Goa, Haryana, and Manipur, where the PRR is greater than one and CI tends towards -1 , also suggesting greater prevalence of thyroid disorder in women with poor socio-economic status. Further, the negative value of CI $(-0.125)$ in Daman and Diu reveals that the prevalence of thyroid disorder is disproportionately concentrated among families belonging to poor and middle wealth quintiles. The states of Lakshadweep, Delhi, Sikkim, and Uttarakhand, where the value of the PRR is 0.00 , show that among these states there is no inequality regarding thyroid disorder between poor and rich women.

Spatial variation in thyroid disorder Given the research hypothesis of no spatial clustering in thyroid disorder across the 640 districts, the results analysed in this section have two major components. First, BiLISA maps and Moran's I provide visual support and spatial autocorrelation between the prevalence of thyroid disorder and some selected socio-economic factors. Second, the spatial autoregression shows the spatial dependence of thyroid disorder on the various background and behavioral characteristics that play a key role in the spatial clustering of thyroid disorder.

Figure 3(A) shows the BiLISA map of women using iodized salt and having a thyroid disorder. Around 62 districts in the country are identified as hotspots, having a higher degree of spatial clustering in the two characteristics under consideration. The Moran's I value, showing a spatial autocorrelation of 0.63 between iodine usage and thyroid disorder prevalence, is very high and statistically significant. Most of these districts are in states such as West Bengal, Kerala, Jammu Kashmir and some parts of Odisha. These findings are strongly indicative of the fact that thyroid disorder not only occurs because of iodine deficiency but can also be associated with a sedentary lifestyle. While in hilly areas the iodine content in the water that people drink is low among the states that are on the plains, it is people's sedentary lifestyle and dietary habits which could be the key catalyst behind thyroid disorder. In the state of Kerala; there is a substantial amount of seafood consumption, which could be one of the factors leading to the high prevalence of hypothyroidism. 
Table 3 State and UT wise prevalence of thyroid disorder among women aged 15-49 years by wealth quintiles, poor-rich ratio, and Wagstaff concentration index along with the value of standard error in various States/UTs of India, 2015-16

\begin{tabular}{|c|c|c|c|c|c|c|c|c|}
\hline State/UTs & Poorest & Poorer & Middle & Richer & Richest & PRR & CI & $\mathrm{SE}$ \\
\hline Andaman and Nicobar & 0.0 & 0.7 & 1.4 & 2.2 & 5.5 & 0.00 & 0.41 & 0.06 \\
\hline Andhra Pradesh & 2.8 & 2.3 & 3.0 & 4.0 & 6.5 & 0.44 & 0.19 & 0.03 \\
\hline Arunachal Pradesh & 0.7 & 0.9 & 0.8 & 1.1 & 1.4 & 0.51 & 0.12 & 0.05 \\
\hline Assam & 1.0 & 1.2 & 1.4 & 2.6 & 5.9 & 0.17 & 0.25 & 0.03 \\
\hline Bihar & 0.7 & 1.1 & 1.7 & 2.3 & 4.5 & 0.16 & 0.31 & 0.03 \\
\hline Chandigarh & 0.0 & 0.0 & 0.0 & 2.8 & 7.1 & 0.00 & 0.27 & 0.09 \\
\hline Chhattisgarh & 0.6 & 0.6 & 1.0 & 1.8 & 3.4 & 0.18 & 0.38 & 0.03 \\
\hline Dadra and Nagar Havel & 0.0 & 0.0 & 0.8 & 1.6 & 2.3 & 0.00 & 0.59 & 0.11 \\
\hline Daman and Diu & 0.0 & 0.0 & 0.0 & 0.3 & 0.3 & 0.00 & -0.13 & 0.31 \\
\hline Delhi & 0.0 & 5.9 & 3.1 & 2.3 & 5.5 & 0.00 & 0.17 & 0.04 \\
\hline Goa & 27.5 & 0.5 & 0.8 & 1.5 & 2.1 & 13.05 & 0.09 & 0.11 \\
\hline Gujarat & 0.4 & 0.3 & 0.6 & 0.9 & 1.8 & 0.21 & 0.36 & 0.04 \\
\hline Haryana & 3.4 & 1.7 & 2.0 & 1.5 & 2.6 & 1.30 & 0.09 & 0.03 \\
\hline Himachal Pradesh & 2.4 & 0.6 & 1.3 & 2.1 & 5.0 & 0.48 & 0.35 & 0.04 \\
\hline Jammu and Kashmir & 2.0 & 3.5 & 5.3 & 8.9 & 10.9 & 0.18 & 0.26 & 0.02 \\
\hline Jharkhand & 0.4 & 0.6 & 0.9 & 2.1 & 4.6 & 0.08 & 0.51 & 0.03 \\
\hline Karnataka & 0.9 & 0.9 & 1.1 & 2.1 & 3.3 & 0.26 & 0.22 & 0.03 \\
\hline Kerala & 3.3 & 5.7 & 7.3 & 7.8 & 8.7 & 0.39 & 0.05 & 0.02 \\
\hline Lakshadweep & 0.0 & 0.0 & 6.1 & 5.5 & 5.8 & 0.00 & 0.01 & 0.09 \\
\hline Madhya Pradesh & 0.7 & 0.9 & 1.0 & 1.6 & 3.8 & 0.18 & 0.33 & 0.02 \\
\hline Maharashtra & 0.9 & 0.8 & 1.0 & 1.4 & 3.5 & 0.26 & 0.33 & 0.03 \\
\hline Manipur & 5.1 & 4.1 & 3.8 & 5.8 & 4.2 & 1.22 & 0.04 & 0.03 \\
\hline Meghalaya & 0.3 & 2.2 & 2.2 & 3.4 & 3.2 & 0.10 & 0.15 & 0.04 \\
\hline Mizoram & 0.6 & 0.7 & 1.6 & 1.5 & 2.5 & 0.26 & 0.16 & 0.05 \\
\hline Nagaland & 0.4 & 0.6 & 1.0 & 1.3 & 1.9 & 0.21 & 0.26 & 0.05 \\
\hline Odisha & 0.6 & 0.9 & 1.4 & 2.1 & 4.2 & 0.14 & 0.40 & 0.03 \\
\hline Puducherry & 1.8 & 3.8 & 3.5 & 2.4 & 4.0 & 0.46 & 0.11 & 0.05 \\
\hline Punjab & 0.6 & 1.0 & 1.3 & 1.8 & 3.3 & 0.17 & 0.22 & 0.03 \\
\hline Rajasthan & 0.3 & 0.4 & 1.0 & 1.0 & 2.7 & 0.12 & 0.42 & 0.02 \\
\hline Sikkim & 0.0 & 0.3 & 0.3 & 1.2 & 3.5 & 0.00 & 0.50 & 0.08 \\
\hline Tamil Nadu & 1.2 & 2.2 & 2.2 & 3.0 & 3.7 & 0.33 & 0.15 & 0.02 \\
\hline Telangana & 1.4 & 3.2 & 3.5 & 4.9 & 6.9 & 0.21 & 0.22 & 0.04 \\
\hline Tripura & 0.3 & 0.7 & 1.6 & 4.5 & 7.0 & 0.04 & 0.55 & 0.05 \\
\hline Uttarakhand & 0.0 & 0.7 & 0.8 & 1.4 & 3.0 & 0.00 & 0.41 & 0.04 \\
\hline Uttar Pradesh & 0.5 & 0.6 & 0.8 & 1.4 & 3.7 & 0.14 & 0.44 & 0.02 \\
\hline West Bengal & 1.1 & 1.9 & 3.4 & 5.2 & 8.6 & 0.13 & 0.38 & 0.03 \\
\hline India & 0.7 & 1.1 & 1.8 & 2.7 & 4.3 & 0.17 & 0.33 & 0.00 \\
\hline
\end{tabular}

UT: union territory, PRR: poor-rich ratio, CI: concentration index, SE: standard error

Figure 3(B) shows that around 44 districts of the country have very significant spatial clustering in urban areas, typically found in states like Jammu and Kashmir, Himachal Pradesh, West Bengal, Andhra Pradesh, Kerala, and some districts of states such as Meghalaya. This high prevalence of thyroid disorder, especially subclinical hypothyroidism, among adults without an increase in autoimmunity might be the effect of the transition from iodine deficiency to sufficiency, even though the lack of pre-iodization data makes it difficult to put forward a firm conclusion (Krejbjerg 2015). In the rural areas shown in Fig. 3(C), it can be seen that around 45 districts of the country have very high spatial clustering of thyroid disorder. Most of the districts under the high-high categories are in states such as Jammu and Kashmir, Himachal Pradesh, West Bengal, Andhra Pradesh, Kerala, and some districts of north-eastern states such as Manipur 
Fig. 3 Bivariate LISA maps exploring the spatial distribution of different indicators of thyroid disorder among women aged 15 49 years in India. Note: These maps are only indicative and do not portray the political/ administrative boundaries of India. Some districts of Jammu and Kashmir have no data coverage in the GADM database [GADM database of Global Administrative Areas: GADM maps and data (2018)]. The figures in parentheses are the number of districts in each category

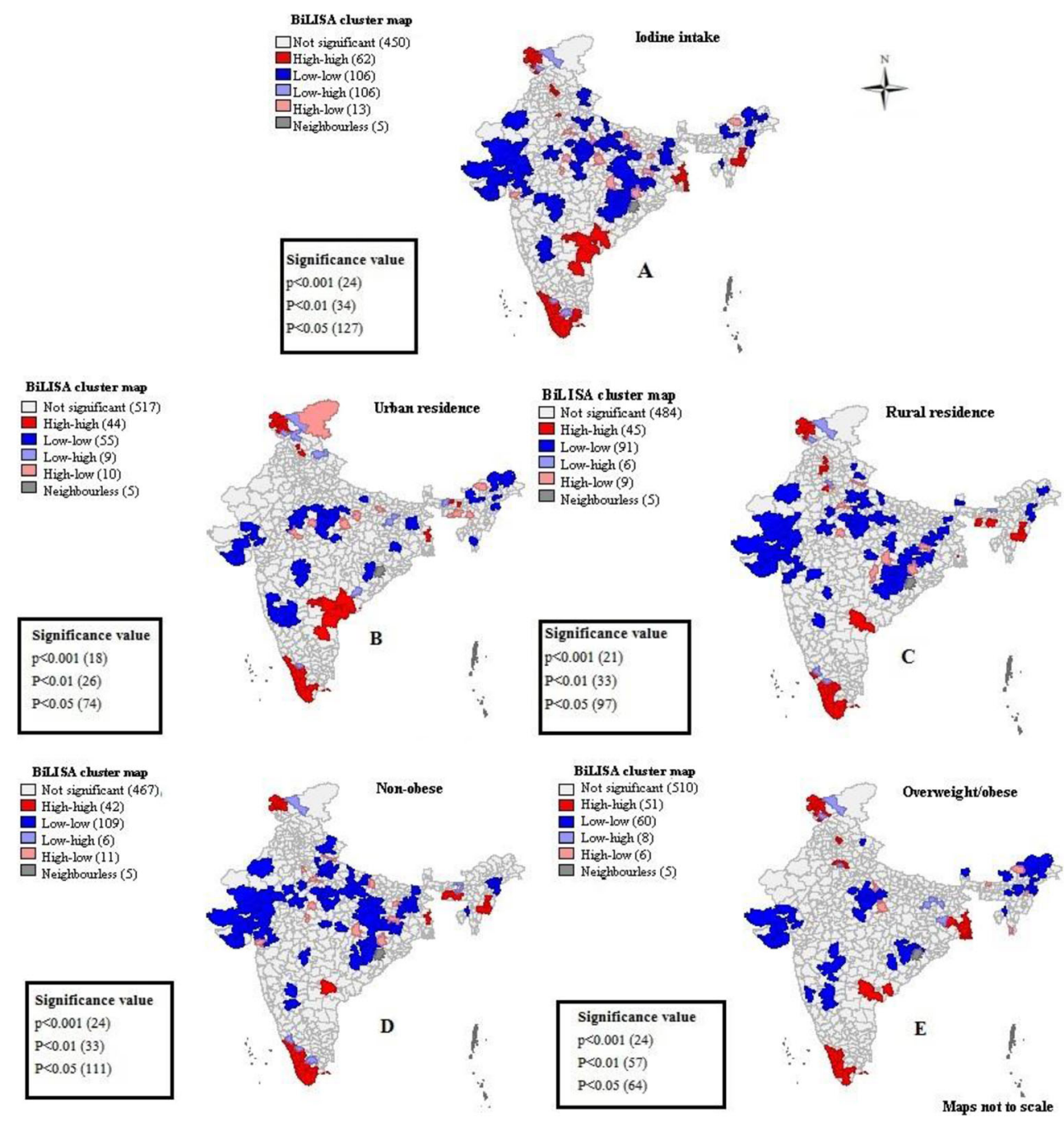

and Nagaland. These coincide almost completely with the same states/region where there is higher spatial clustering in urban areas. In both cases, we have significantly higher values of Moran's I, namely 0.45 for urban and 0.58 for rural areas (see Fig. 4). Further, there is a significantly higher spatial autocorrelation between obesity and thyroid disorder. In the case of non-obese women, there are around 42 districts constituting the hotspots, i.e., showing high-high spatial clustering in the two characteristics under consideration. Most of those districts are from the states of Jammu and Kashmir, namely Sopore, Rajouri, Jammu, Kathua, and almost all the districts of the state of Kerala. Other districts are in the states of Telangana, West Bengal, Meghalaya, Nagaland, Mizoram, and Tamil Nadu [see Fig. 3(D)].

In Fig. 3(E), the hotspots of spatial autocorrelation between thyroid prevalence and those who are overweight or obese are illustrated. There are around 51 hotspot districts in the country, mainly concentrated in the states of Jammu and Kashmir, West Bengal, Himachal Pradesh, Telangana, Andhra Pradesh, and Kerala. They include Kupwara, Nandiwara, Baramulla, Sopore, Rezai, South 24 Parganas, Hooghly, Howrah, South
Dinajpur, Bankura, Nalgonda, Guntur, Elura, Kasaragod, Kannur, Wayanad, Kozhikode, Malappuram, Thiruvananthapuram, Kollam, Alappuzha, Pathanamthitta, Nagercoil, Tirunelveli, Virudunagar and various others. There was very significant clustering in all the aforementioned districts. The health status of women, whether obese or nonobese, also have significant Moran's I values namely 0.44 and 0.6 , respectively (see Fig. 4).

The results of spatial autocorrelation with the application of BiLISA maps and Moran's I established a need to analyse the spatial dependence in the prevalence of thyroid across different districts of India. To decide the suitability of the model for analysis, two sets of tests on Lagrange multipliers (LM) and robust LM were used with the help of the White test in the OLS model. The White test reveals the significance of LM lag as well as LM error, allowing them to be compared. A relatively larger value of LM error compared with the LM lag, and a larger value of adjusted $\mathrm{R}^{2}$, explain the better model adequacy, while lower values of the Akaike info criterion and Schwarz criterion justify its better suitability. These guided us to apply the LM error model to analyse the spatial 
Fig. 4 Moran's I scatter plot showing spatial dependence of women aged 15-49 years who reported to be suffering from thyroid disorder with different indicators, India 2015-16

\section{Moran's I scatter nlot}

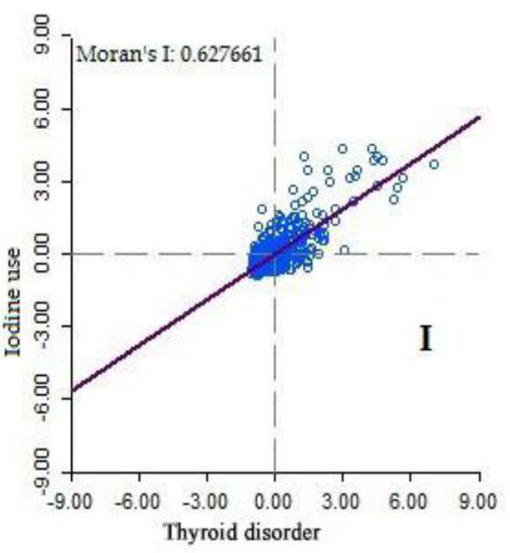

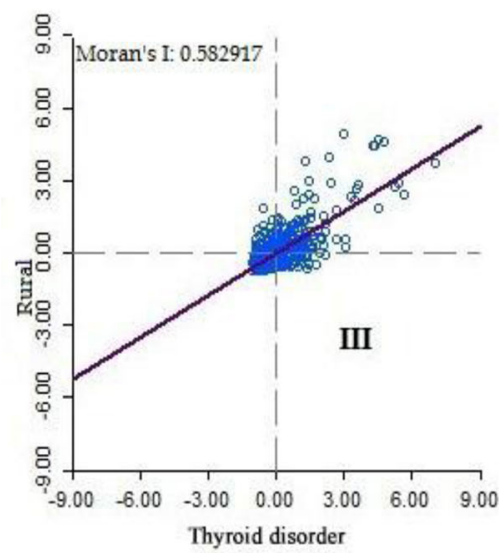
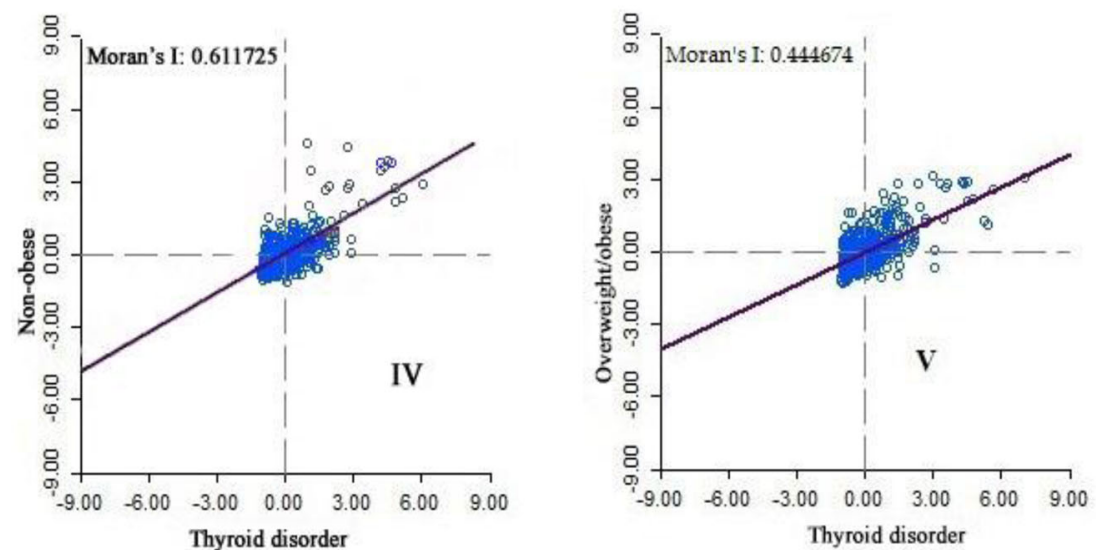

dependence of thyroid disorder with the various predictors included in the model.

Results of the spatial error model on the spatial dependence of thyroid disorder on proximate determinants and other meso-variables are presented in Table 4. The autoregressive coefficient was 0.71 , with higher spatial clustering in the outcome variable thyroid accounting for the geographical pattern of measured and unmeasured independent variables. The findings imply that for the prevalence of thyroid disorder in India, space matters significantly. When spatial weights are taken into consideration in the model, the spatial regression model becomes noticeably stronger in predicting the prevalence of thyroid disorder. Being overweight or obese (BMI $\geq 25 \mathrm{~kg} /$ $\mathrm{m}^{2}$ ) and from SC/ST households are the key predictors significantly explaining the spatial dependence of thyroid disorder. However, the direction of the association is in the opposite direction. With increasing overweight/obesity, the chances of suffering from thyroid disorder also increases, while it decreases in case of those from SC/ST. This may be primarily because SC/ST women mostly work as daily wage laborers or 
Table 4 Summary of spatial error model and maximum likelihood estimation for thyroid disorder by some selected background characteristics across different districts of India, 2015-16

\begin{tabular}{|c|c|c|c|}
\hline Coefficient & OLS & & Spatial regression (error model) \\
\hline R-squared & 0.377 & & 0.655 \\
\hline Log likelihood & -1168.40 & & -1021.33 \\
\hline Akaike info criterion & 2350.81 & & 2056.67 \\
\hline Schwarz criterion & 2382.04 & & 2087.90 \\
\hline Background characteristic & Coefficient & z-value & Probability \\
\hline Constant & 1.5099 & 3.22 & 0.00 \\
\hline Urban residence & -0.0005 & -0.15 & 0.88 \\
\hline Not using iodide salt & -0.0037 & -0.41 & 0.68 \\
\hline $\mathrm{SC} / \mathrm{ST}$ caste & -0.0100 & -3.26 & 0.00 \\
\hline Overweight/obese & 0.0703 & 5.63 & 0.00 \\
\hline No education & -0.0006 & -0.08 & 0.94 \\
\hline BPL households & -0.0116 & -2.06 & 0.04 \\
\hline Lambda & 0.7108 & 21.62 & 0.00 \\
\hline
\end{tabular}

OLS: ordinary least squares, SC: scheduled caste, ST: scheduled tribe, BPL: below poverty line

on the family farm. These arguments are also reinforced by the spatial dependence of thyroid disorder on wealth quintiles, which is negative though not significant. Findings indicate that physical activity reduces the chances of suffering from thyroid disorder. It is worth mentioning that the inclusion of spatial weights in the model increased its predicting power from $38 \%$ in the case of OLS to nearly $65 \%$ in the spatial regression model.

\section{Discussion}

Our findings on spatial heterogeneity in the prevalence of thyroid disorder among women in their reproductive ages of 15-49 years in India is based on a nationally representative sample where a total of 15,303 women reported that they were suffering from medically diagnosed thyroid disorders. It is evident that consumption of iodized salt (93\%) in NFHS-4 has increased substantially over NFHS-3 (74\%), which has implications for the lower level of thyroid disorders among women in the country. A high level of iodized salt utilization in India has been the consequence of massive international efforts and initiatives by governments to achieve USI. There is a ban on the selling of non-iodized salts in India, citing public health issues. Yet, after decades, the pattern is still not balanced, with southern states lagging behind other parts of the country. Results show high spatial heterogeneity in IDD burden across the diverse agro-climatic regions of the country.

It is observed that the incidence of thyroid disorder increases the higher the education and wealth quintile, which may suggest an impact arising from dietary and lifestyle changes associated with women from more elite subgroups. This finding is in line with existing literature, which establishes that lack of physical activity, coupled with imbalanced dietary make-up, is pushing people, including youngsters, towards hypothyroidism, which has become a severe concern these days (Panagiotou et al. 2017; Sanyal and Raychaudhuri 2016). Another important reason for the higher prevalence of thyroid disorders among women with better education and wealth quintiles could be polycystic ovarian disease, which is quite prevalent among overweight women (Janssen et al. 2004).

Counterintuitively, the results also show that people using iodized salt are more likely to suffer from thyroid disorder $(\mathrm{OR}=1.14)$. As discussed earlier, this is indicative of lifestyle-related factors acting as significant contributory factors, especially among those who are educated and from economically better-off households. Thyroid disorder is also prevalent in regions where iodine intake is enough to meet the requirements of the human body; the reason for this unconventional prevalence of disorders could be due to multiple nutritional and environmental factors (Ingenbleek and De Visscher 1979).

The southern states of the country have high thyroid prevalence, which, as we have seen, is because of comparatively lower levels of usage of iodized salt as compared to other states. However, there is an anomaly in the case of Kerala, where both iodine consumption and thyroid disorder are remarkably high. In hilly areas too, the same pattern is observed, where the reason could be low iodine content in the water and soil. The most plausible explanation for the rising incidence of thyroid cases in the region, especially in Kerala, could be over-diagnosis and reporting (Mathew and Mathew 2017). Kerala also has a higher socio-economic and educational status than the rest of the country. Higher socio-economic status in a population may increase thyroid rates and hence the 
higher reported rates (Altekruse et al. 2015; Levi et al. 1991; Reitzel et al. 2014). Further micro-investigations may unveil causes of hypothyroidism other than the nutritional deficiency of iodine. Numerous studies have concluded that mountainous regions are IDD hosts because of the low iodine content in the soil, due to melting glaciers leaching iodine out of the ground below (Canaris et al. 2000; Laurberg et al. 1998; Sawin et al. 1985).

There are around 19 states/UTs in the country which have a PRR in the context of thyroid disorder higher than the national average. Studies have shown association and concluded that an increased risk of hyperthyroidism correlates with a high intake of iodine-rich food such as seafood (Kolonel et al. 1990; Ron et al. 1987). Another study talks about seafood having a protective effect (Franceschi et al. 1989). Goa has an abnormally higher prevalence of women belonging to the most deprived quintile and having a thyroid disorder, a reason for which could be higher alcohol consumption in the state. Higher intake of seafood, the consumption of indigenous alcoholic drinks, and the staple foods that people eat could be other significant contributing factors. Various studies exist showing a link between high alcohol intake and thyroid disorder (Franceschi et al. 1989; Kolonel et al. 1990; Ron et al. 1987).

A robust spatial clustering was observed in the case of women who were obese $\left(\mathrm{BMI}>25 \mathrm{~kg} / \mathrm{m}^{2}\right)$. This provides evidence that thyroid disorder is present among obese women, which may be because of hypothyroidism. These findings are consistent with the results of a study by Panagiotou et al. (2017). They highlighted that body fat accumulation and lack of exercise, which are the surrogate markers of a sedentary lifestyle, influence thyroid nodule size and could predict some ultra-sonographic characteristics, such as hypoechogenicity and internal vascularity. Therefore, routine thyroid examination of obese patients and the promotion of an active lifestyle can act to prevent thyroid nodule formation and progression to malignancy. Lack of physical activity, coupled with an unbalanced diet is pushing more people, including youngsters, towards hypothyroidism - an underactive thyroid that tends to mirror the slowing down of physical processes, resulting in insufficient thyroid hormone (Simpson and Hertoghe 2009).

\section{Conclusions}

The findings of this study portray that the prevalence of thyroid disorder in India correlates appreciably with spatial and ecological factors. When spatial weights are included in the model, the spatial regression model significantly predicts the prevalence of thyroid disorder. The prevalence of thyroid disorder was relatively lower among SC/ST women. A plausible explanation of this finding could be the fact that women from these subgroups are engaged in extreme physical activities as compared to others. As discussed, the spatial dependence of the thyroid disorder exists among women who enjoy better economic status. Overweight or obese women were more likely to suffer from IDD. The relation of higher BMI and thyroid malfunctions in the human body has been widely discussed elsewhere. Fat accumulation and lack of exercise influence thyroid nodule size and affect the health of an individual (Mueller et al. 2009; Singla et al. 2015). Sedentary lifestyle leads to complex syndromes such as polycystic ovarian disease, which act as a strong linkage with thyroid disorders, especially hypothyroidism. The findings unveil an urgent need to effectively integrate USI and a strategy to reduce non-iodized salt consumption, in order to prevent the risk of recurrence of iodine deficiency. This can only be achieved by generating the sustained interest and participation of the entire population in activities geared toward IDD elimination, including thyroid disorder.

\section{Limitations of this study}

The estimated prevalence of thyroid disorder analysed in this paper is based on medically diagnosed but self-reported cases among women of reproductive ages in India. There is a relatively higher prevalence of thyroid disorder among the elderly population; hence, the prevalence analysed in this paper may be somewhat lower than the actual burden of thyroid disorder in India.

Abbreviations AIC, Akaike information criterion; BiLISA, Bivariate local indicators of spatial association; BMI, Body mass index; CI, Concentration index; GIS, Geographic Information System; IDD, Iodine deficiency disorders; IIPS, International Institute for Population Sciences; LISA, Local indicators of spatial association; LM, Lagrange multiplier; MoHFW, Ministry of Health and Family Welfare; NCDs, Non-communicable disease; NFHS, National Family Health Survey; OLS, Ordinary least square; PRR, Poor-rich ratio; SC, Scheduled caste; SEM, Spatial error model; ST, Scheduled tribe; TD, Thyroid disorder; USI, Universal salt iodization; UT, Union territory; WHO, World Health Organization

Acknowledgments The authors are grateful to all study participants. This research received no specific grant from any funding agency, commercial entity, or not-for-profit organisation. We thank the reviewers from the journal for giving their useful comments for the improvement of this article.

Authors' contribution All authors contributed to the study conception and design. Material preparation, data collection, and analysis were performed by S.K Singh, Jitendra Gupta and Aditi. The first draft of the manuscript was written by Aditi, and all authors commented on previous versions of the manuscript. All authors read and approved the final manuscript.

Conceptualization: S.K Singh; methodology: S.K Singh, Jitendra Gupta; formal analysis and investigation: Jitendra Gupta, Aditi; writing — original draft preparation: Aditi; writing — review and editing: S.K Singh; funding acquisition: not required; resources: not required; supervision: S.K Singh. 
Availability of data and materials The data is available online for public use at the International Institute for Population Sciences (IIPS), Mumbai website. IIPS was the nodal agency for the NFHS-4 survey; therefore, IIPS has a data centre able to make data available. Being faculty members and students of this institute, we were able to access the data easily from the institute's data centre.

\section{Declarations}

Ethics approval This study used a secondary dataset which did not contain any identifiable information of the survey participants. This dataset is readily available in the public domain for research purposes, hence no approval was required from any institutional review board, as no question of human subject protection arises in this case.

Disclosure of potential conflicts of interest The authors declare that there is no conflict of interest.

Competing interests The authors declare that no competing interests exist.

Consent to participate The study uses a secondary source of data, and informed consent was obtained from all individual participants included in the survey while the survey data was collected.

Consent to publish All the three authors have given their consent to publish the article.

Open Access This article is licensed under a Creative Commons Attribution 4.0 International License, which permits use, sharing, adaptation, distribution and reproduction in any medium or format, as long as you give appropriate credit to the original author(s) and the source, provide a link to the Creative Commons licence, and indicate if changes were made. The images or other third party material in this article are included in the article's Creative Commons licence, unless indicated otherwise in a credit line to the material. If material is not included in the article's Creative Commons licence and your intended use is not permitted by statutory regulation or exceeds the permitted use, you will need to obtain permission directly from the copyright holder. To view a copy of this licence, visit http://creativecommons.org/licenses/by/4.0/.

\section{References}

Altekruse S, Das A, Cho H, Petkov V, Yu M (2015) Do US thyroid cancer incidence rates increase with socioeconomic status among people with health insurance? An observational study using SEER population-based data. BMJ Open 5(12):e009843. https://doi.org/ 10.1136/bmjopen-2015-009843

Anselin L, Syabri I, Kho Y (2010) GeoDa: An introduction to spatial data analysis. In Handbook of applied spatial analysis. In: Fischer M, Getis A (eds) Handbook of applied spatial analysis. Springer, Berlin, Heidelberg, pp 73-89. https://doi.org/10.1007/978-3-64203647-7 5

Bora JK, Raushan R, Lutz W (2019) The persistent influence of caste on under-five mortality: factors that explain the caste-based gap in high focus Indian states. PLoS One 14(8):e0211086. https://doi.org/10. 1371/journal.pone. 0211086

Bray G, Fisher D, Chopra I (1976) Relation of thyroid hormones to bodyweight. Lancet 307(7971):1206-1208. https://doi.org/10.1016/ S0140-6736(76)92158-9
Canaris GJ, Manowitz NR, Mayor G, Ridgway EC (2000) The Colorado Thyroid Disease Prevalence Study. Arch Intern Med 160(4):526534. https://doi.org/10.1001/archinte.160.4.526

Ciarrocca M, Tomei F, Caciari T, Cetica C, Andrè JC et al (2012) Exposure to arsenic in urban and rural areas and effects on thyroid hormones. Inhal Toxicol 24(9):589-598. https://doi.org/10.3109/ 08958378.2012 .703251

Diosady L, Alberti J, Mannar MV, FitzGerald S (1998) Stability of iodine in iodized salt used for correction of iodine-deficiency disorders. II. Food Nutr Bull 19(3):240-250. https://doi.org/10.1177/ 156482659801900306

Engle PL, Black MM, Behrman JR, De Mello MC, Gertler PJ et al (2007) Strategies to avoid the loss of developmental potential in more than 200 million children in the developing world. Lancet 369(9557): 229-242. https://doi.org/10.1016/S0140-6736(07)60112-3

Franceschi S, Fassina A, Talamini R, Mazzolini A, Vianello S et al (1989) Risk factors for thyroid cancer in northern Italy. Int J Epidemiol 18(3):578-584. https://doi.org/10.1093/ije/18.3.578

GADM maps and data (2018) Spatial files for India. https://gadm.org/ index.html

Guay B, Johnson-Obaseki S, McDonald JT, Connell C, Corsten M (2014) Incidence of differentiated thyroid cancer by socioeconomic status and urban residence: Canada 1991-2006. Thyroid 24(3):552555. https://doi.org/10.1089/thy.2013.0308

Hall JE (2015) Pocket companion to Guyton and Hall textbook of medical physiology: eBook version. Elsevier Health Sciences, Amsterdam

IIPS and ICF (2017) India National Family Health Survey NFHS-4 2015-16. IIPS and ICF, Mumbai

Ingenbleek Y, De Visscher M (1979) Hormonal and nutritional status: critical conditions for endemic goiter epidemiology? Metabolism 28(1):9-19. https://doi.org/10.1016/0026-0495(79)90162-8

IIPS (2007) National Family Health Survey (NFHS-3), 2005-06: India. International Institute for Population Sciences, Mumbai

Janssen OE, Mehlmauer N, Hahn S, Offner AH, Gartner R (2004) High prevalence of autoimmune thyroiditis in patients with polycystic ovary syndrome. Eur J Endocrinol 150(3):363-370

Kakwani N, Wagstaff A, Van Doorslaer E (1997) Socioeconomic inequalities in health: measurement, computation, and statistical inference. J Econ 77(1):87-103. https://doi.org/10.1016/S0304-4076(96) 01807-6

Kapil U (2007) Health consequences of iodine deficiency. Sultan Qaboos Univ Med J 7(3):267

Kolonel LN, Hankin JH, Wilkens LR, Fukunaga FH, Hinds MW (1990) An epidemiologic study of thyroid cancer in Hawaii. Cancer Causes Control 1(3):223-234. https://doi.org/10.1007/BF00117474

Krejbjerg A (2015) Salt iodization in Denmark and individual changes in thyroid size, thyroid nodularity and serum thyroglobulin. PhD thesis, Aalborg University Hospital, Denmark https://doi.org/10.5278/ vbn.phd.med.00003

Laurberg P, Pedersen KM, Hreidarsson A, Sigfusson N, Iversen E et al (1998) Iodine intake and the pattern of thyroid disorders: a comparative epidemiological study of thyroid abnormalities in the elderly in Iceland and in Jutland, Denmark. J Clin Endocrinol Metab 83(3): 765-769. https://doi.org/10.1210/jcem.83.3.4624

Levi F, Franceschi S, La Vecchia C, Negri E, Gulie C et al (1991) Previous thyroid disease and risk of thyroid cancer in Switzerland. Eur J Cancer Clin Oncol 27(1):85-88. https://doi.org/10.1016/02775379(91)90069-P

Mathew IE, Mathew A (2017) Rising thyroid cancer incidence in southern India: an epidemic of overdiagnosis? JES 1(5):480-487. https:// doi.org/10.1210/js.2017-00097

Meisinger C, Ittermann T, Wallaschofski $\mathrm{H}$, Heier M, Below $\mathrm{H}$ et al (2012) Geographic variations in the frequency of thyroid disorders and thyroid peroxidase antibodies in persons without former thyroid 
disease within Germany. Eur J Endocrinol 167(3):363-371. https:// doi.org/10.1530/EJE-12-0111

Miller D, Mumford P, Stock M (1967) Gluttony: 2. Thermogenesis in overeating man. Am J Clin Nutr 20(11):1223-1229. https://doi.org/ 10.1093/ajcn/20.11.1223

Mioto VC, Gomes AC, de Camargo RY, Borel AR, Catarino RM et al (2018) High prevalence of iodine deficiency in pregnant women living in adequate iodine area. Endocr Connect 7(5):762-767. https://doi.org/10.1530/EC-18-0131

Mueller A, Schöfl C, Dittrich R, Cupisti S, Oppelt PG et al (2009) Thyroid-stimulating hormone is associated with insulin resistance independently of body mass index and age in women with polycystic ovary syndrome. Hum Reprod 24(11):2924-2930. https://doi. org/10.1093/humrep/dep285

Panagiotou G, Komninou D, Anagnostis P, Linardos G, Karoglou E et al (2017) Association between lifestyle and anthropometric parameters and thyroid nodule features. Endocrine 56(3):560-567. https://doi. org/10.1007/s12020-017-1285-6

Raushan R, Mutharayappa R (2014) Social disparity in curative care: determining factors across social groups in rural India. J Social Econ Devt 16(2):204-225. https://doi.org/10.1177/ 2394481118818594

Reitzel LR, Nguyen N, Li N, Xu L, Regan SD et al (2014) Trends in thyroid cancer incidence in Texas from 1995 to 2008 by socioeconomic status and race/ethnicity. Thyroid 24(3):556-567. https://doi. org/10.1089/thy.2013.0284

Rhyne RL, Gehlbach SH (1979) Effects of an educational feedback strategy on physician utilization of thyroid function panels. J Fam Pract 8(5):1003-1007

Ron E, Kleinerman RA, Boice JD Jr, LiVolsi VA, Flannery JT et al (1987) A population-based case-control study of thyroid cancer. J Natl Cancer Inst 79(1):1-12. https://doi.org/10.1093/jnci/79.1.1

Sanyal D, Raychaudhuri M (2016) Hypothyroidism and obesity: an intriguing link.Indian J Endocrinol Metab 20(4):554. https://doi.org/ $10.4103 / 2230-8210.183454$

Sawin CT, Castelli WP, Hershman JM, McNamara P, Bacharach P (1985) The aging thyroid: thyroid deficiency in the Framingham
Study. Arch Intern Med 145(8):1386-1388. https://doi.org/10. 1001/archinte. 1985.00360080056006

Schectman JM, Elinsky EG, Pawlson LG (1991) Effect of education and feedback on thyroid function testing strategies of primary care clinicians. Arch Intern Med 151(11):2163-2166. https://doi.org/10. 1001/archinte.1991.00400110027006

Simpson K, Hertoghe T (2009) The women's guide to thyroid health: comprehensive solutions for all your thyroid symptoms: New Harbinger Publications, Oakland,CA, USA

Sims EA, Danforth Jr E, Horton ES, Bray GA, Glennon J et al (1973) Endocrine and metabolic effects of experimental obesity in man. Recent Prog Horm Res 29:457-496. https://doi.org/10.1016/B9780-12-571129-6.50016-6

Singla R, Gupta Y, Khemani M, Aggarwal S (2015) Thyroid disorders and polycystic ovary syndrome: an emerging relationship. Indian J Endocrinol Metab 19(1):25-29. https://doi.org/10.4103/2230-8210. 146860

Unnikrishnan AG, Menon UV (2011) Thyroid disorders in India: an epidemiological perspective. Indian J Endocrinol Metab 15(Suppl2):S78. https://doi.org/10.4103/2230-8210.83329

Wagstaff A, Doorslaer EV (2004) Overall versus socioeconomic health inequality: a measurement framework and two empirical illustrations. Health Econ 13(3):297-301. https://doi.org/10.1002/hec.822

WHO (2001) Assessment of iodine deficiency disorders and monitoring their elimination: a guide for programme managers. WHO, Geneva. https://apps.who.int/iris/bitstream/handle/10665/61278/WHO NHD_01.1.pdf

WHO (2007) Assessment of iodine deficiency disorders and monitoring their elimination: a guide for programme managers. WHO, Geneva. https://apps.who.int/iris/bitstream/handle/10665/43781/ 9789241595827_eng.pdf

Publisher's note Springer Nature remains neutral with regard to jurisdictional claims in published maps and institutional affiliations. 